\title{
Comparative study of the catalytic growth of patterned carbon nanotube films
}

\author{
Christian Klinke and Jean-Marc Bonard \\ Institut de Physique des Nanostructures, \\ Ecole Polytechnique Fédérale de Lausanne, \\ CH - 1015 Lausanne, Switzerland \\ Klaus Kern \\ Institut de Physique des Nanostructures, \\ Ecole Polytechnique Fédérale de Lausanne, \\ CH - 1015 Lausanne, Switzerland \\ and \\ Max-Planck-Institut für Festkörperforschung, \\ D - 70569 Stuttgart, Germany
}

\begin{abstract}
Three different catalysts ( $\mathrm{Fe}, \mathrm{Ni}$, Co nitrates dissolved in ethanol) were patterned on a $\mathrm{SiO}_{2} / \mathrm{Si}$ substrate and multi-wall carbon nanotubes were grown by catalytic decomposition of acetylene. We compare the growth of the carbon nanostructures in the temperature range between $580^{\circ} \mathrm{C}$ and $1000^{\circ} \mathrm{C}$. With our experimental set-up the catalyst solutions of cobalt and nickel were found to be less efficient than the one of iron. An optimal production of multi-wall nanotubes was observed at temperatures between $650^{\circ} \mathrm{C}$ and $720^{\circ} \mathrm{C}$ with the iron solution as catalyst. We found a tendency towards thicker structures with higher temperatures. Finally, we suggest a mechanism for the growth of these carbon structures.
\end{abstract}

\section{INTRODUCTION}

Carbon nanostructures like fullerenes [1], nanotubes [2], nano-onions [3] and nano-horns [4] have attracted much interest recently. In particular their mechanical and electronic properties are the subject of intensive studies [5, 6]. Beside the fundamental interest in their physical and chemical properties, there are already some applications based on carbon nanotubes. For example, they are capable to work as efficient field emitters [7] and can form a basis for very robust fibers [8]. Nanotubes can be produced by arc discharge 2], by laserablation 9] or by chemical vapor deposition techniques (CVD) 10, 11, 12, 13, 14, 15, 16]. CVD is currently the most promising and flexible method with regard to applications, but our understanding of the influence of the catalyst and the deposition parameters on the nanotube growth is still fragmentary.

We use here the CVD method in combination with microcontact printing to grow patterned films of multi-wall carbon nanotubes 12]. Microcontact printing $(\mu \mathrm{CP})$ has become an often applied method in the last few years because it is a simple way to define chemical patterns on a variety of substrates [17, 18, 19]. We use this method to selectively deliver a catalyst to the substrate surface, which in turn activates the growth of nanotubes [12]. The advantage of the patterning is that one can compare the regions with and without catalyst, and thus exactly determine the role of the catalyst. In order to better un-

\footnotetext{
*Electronic address: christian@klinke.org

${ }^{\dagger}$ Present address: Rolex S.A., 3-7 Rue Francois-Dussaud, 1211 Geneva 24, Switzerland.
}

derstand the catalytic growth we systematically examined the parameters temperature, catalyst composition and concentration.

\section{EXPERIMENTAL METHODS}

\section{A. Synthesis of nano-structured material}

$<100>$-oriented boron doped silicon with the native $\mathrm{SiO}_{2}$ oxide layer was used as substrate. The stamps for $\mu \mathrm{CP}$ were prepared by curing poly(dimethyl)siloxane (PDMS) for at least $12 \mathrm{~h}$ at $60^{\circ} \mathrm{C}$ on a structured master prepared by contact photolithography. The width of the square patterns on the wafer is $5 \mu \mathrm{m}$. The stamps were subsequently hydrophilized by an oxygen plasma treatment $\left(\mathrm{O}_{2}\right.$ pressure $\sim 0.8$ mbar, load coil power $\sim 75 \mathrm{~W}$, $60 \mathrm{~s}$ ). The stamp was loaded with $0.2 \mathrm{ml}$ of catalyst solution for $30 \mathrm{~s}$ and then dried in a nitrogen stream for $10 \mathrm{~s}$.

The solutions were $\mathrm{Fe}\left(\mathrm{NO}_{3}\right)_{3} \cdot 9 \mathrm{H}_{2} \mathrm{O}, \mathrm{Ni}\left(\mathrm{NO}_{3}\right)_{2} \cdot 6 \mathrm{H}_{2} \mathrm{O}$ or $\mathrm{Co}\left(\mathrm{NO}_{3}\right)_{2} \cdot 6 \mathrm{H}_{2} \mathrm{O}$ dissolved in ethanol at concentrations between 50 and $200 \mathrm{mM}$. The solutions were used $12 \mathrm{~h}$ after preparation because the metallic ions in the solution form chemical complexes which become larger with time. A period of $12 \mathrm{~h}$ for this "aging" of the solution was found to be ideal for the catalytic growth of nanotubes [12]. The printing was performed by placing the stamp on the surface of the $\mathrm{SiO}_{2} / \mathrm{Si}$ wafer for $3 \mathrm{~s}$.

The samples were placed in a horizontal flow reactor (quartz tube of $14 \mathrm{~mm}$ diameter in a horizontal oven) directly after the printing. The treatment in the CVD oven proceeded in three steps. In the first step, the catalyst was annealed for $20 \mathrm{~min}$ under a flow of $80 \mathrm{ml} / \mathrm{min}$ of nitrogen to roughen the surface of the catalyst and to 
clean the reactor atmosphere. The actual deposition was performed with $80 \mathrm{ml} / \mathrm{min}$ of nitrogen plus $20 \mathrm{ml} / \mathrm{min}$ of acetylene (carbon source for the catalytic growth) at atmospheric pressure for $30 \mathrm{~min}$. The third step was a final annealing of $10 \mathrm{~min}$. under $80 \mathrm{ml} / \mathrm{min}$ of nitrogen. The same temperature was used throughout the entire procedure, which implies that a change of the temperature affected all the steps.

\section{B. Characterization techniques}

Scanning electron microscopy (SEM) was performed to analyze the microstructures in plan view. A Philips XL 30 microscope equipped with a field emission gun (FEG) operating at an acceleration voltage between 2 and $5 \mathrm{kV}$, a working distance of typically $10 \mathrm{~mm}$, and in secondary electron (SE) image mode was used.

The growth morphology of the tubular structures and their crystallinity were controlled by transmission electron microscopy (TEM). For this purpose a Philips EM 430 microscope equipped with a Gatan image plate operating at $300 \mathrm{kV}$ (point resolution $0.3 \mathrm{~nm}$ ) was used.

\section{RESULTS}

We studied systematically the influence of (a) the catalyst solutions containing iron, nickel or cobalt ions, (b) the deposition temperature and (c) the concentration of the catalyst on the nanotube growth. We used concentrations of $50 \mathrm{mM}$ and $100 \mathrm{mM}$ of the three catalysts at temperatures between $580^{\circ} \mathrm{C}$ and $1000^{\circ} \mathrm{C}$ in $70^{\circ} \mathrm{C}$ steps. For the catalyst iron, which produced the highest amount of nanotubes, we also examined samples with a concentration of $150 \mathrm{mM}$ and $200 \mathrm{mM}$ at $650^{\circ} \mathrm{C}$.

After the catalytic growth of the structures, the observation by SEM showed a homogeneous growth over the whole sample surface $\left(>1 \mathrm{~cm}^{2}\right.$, Fig. 1). The nanotubes grow only where the catalyst has been printed, and the bare substrate is free of any carbon form for growth temperatures below $800^{\circ} \mathrm{C}$.

As displayed in Fig. 2 2 we found that the use of the iron catalyst resulted in the highest fidelity of replication of the square pattern, whereas the use of a pure nickel or cobalt solution resulted in inferior patterning. Because of the wetting behavior on the stamp [12], the nickel and the cobalt solutions produced one drop on each square structure of the stamp, which were transferred to the substrate. As a result, the patterns obtained with cobalt and nickel are small and of irregular, circle-like shape. At concentrations higher than $100 \mathrm{mM}$ the printing of the iron solution became also more difficult. XPS and TEM experiments have shown that the printed iron catalyst consists of a gel-like material of partially hydrolyzed $\mathrm{Fe}(\mathrm{III})$ nitrate that forms a porous and continuous $\mathrm{Fe}_{2} \mathrm{O}_{3}$ film after annealing [20]. We assume that the printed catalysts nickel and cobalt are of a similar structure.
The comparison of the three catalysts shows that iron produced the highest density of carbon structures at any considered temperature, as seen in Fig. 2 Nickel and cobalt turned out to be not as good catalysts as iron, as we found only few nanotubes at $720^{\circ} \mathrm{C}$ with $100 \mathrm{mM}$ nickel and cobalt solutions. At $1000^{\circ} \mathrm{C}$, the printed nickel and the cobalt solution initiated the growth of spherical carbon structures, and iron caused the growth of thick worm-like structures.

There is a tendency towards thicker structures with increasing temperature [21], as shown in Fig. [3 for iron. The catalytic growth of nanotubes started at a temperature of $620^{\circ} \mathrm{C}$, but we observed only a few nanotubes at this temperature. A uniform coverage of each printed square was obtained at temperatures of $650^{\circ} \mathrm{C}$ and higher. The thinnest nanotubes were found at $650^{\circ} \mathrm{C}$ with iron as catalyst. The highest density of nanotubes was observed at $720^{\circ} \mathrm{C}$. Using catalyst concentrations of $100 \mathrm{mM}$ we found relatively thick worm-like structures at temperatures exceeding $930^{\circ} \mathrm{C}$ ("carbon worms"). These structures grew to a diameter of up to $1 \mu \mathrm{m}$. Furthermore, the acetylene starts to dissociate in the gas phase at temperatures above $800^{\circ} \mathrm{C}$ and the resultant carbon forms a amorphous continuous layer on the silicon surface of all samples. This layer gets also thicker with the temperature.

Fig. 4 shows clearly that the use of higher catalyst concentrations resulted in an increase of the nanotube density. The nanotubes reached lengths of several $\mu \mathrm{m}$ with a diameter up to $25 \mathrm{~nm}$. Transmission electron microscopy (TEM) of the samples obtained at $650^{\circ} \mathrm{C}$ using the $50 \mathrm{mM}$ iron catalyst confirmed that the structures are well-graphitized and well-separated multiwalled nanotubes which are not filled (Fig. 5). Most of them have open ends and some nanotubes contain encapsulated catalyst particles. These particles are aligned in the growth direction and of prolate shape. They have diameters of about $8 \mathrm{~nm}$ and lengths of about $16 \mathrm{~nm}$.

\section{DISCUSSION}

We suppose that the mechanism of the catalytic growth of carbon nanotubes is similar to the one described by Kanzow et al. 22]. The acetylene is dissociated catalytically at facets of well defined crystal orientation of a small metal (oxide) particle. The resulting hydrogen $\mathrm{H}_{2}$ is removed by the gas flow whereas the carbon diffuses into the particle. For unsaturated hydrocarbons this process is highly exothermic. When the particle is saturated with carbon, the carbon segregates on another, less reactive surface of the particle, which is an endothermic process. The resulting temperature gradient supports the diffusion of carbon through the particle. To avoid dangling bonds, the carbon atoms assemble in a $\mathrm{sp}^{2}$ structure at the cooler side of the particle, which leads to the formation of a nanotube.

The growth of nanotubes starts at temperatures of 
$620^{\circ} \mathrm{C}$ because there is enough mobility of the atoms of the catalyst to enable the diffusion of the carbon through the particle and to start the dynamic of the catalytic construction of carbon nanotubes. At temperatures above $800^{\circ} \mathrm{C}$ the acetylene starts to dissociate already in the gas phase. The carbon in the gas flow of acetylene and nitrogen forms carbon flakes which will be adsorbed on the surface of the sample as well as on the surface of the structures (see Ref. 23]). Since the acetylene is not completely dissociated and the catalytic growth proceeds, the nanotubes will still grow and be covered with a layer of carbon formed by the carbon flakes. The structures get thicker with temperature because the proportion between dissociated and molecular acetylene increases.

We found only few nanotubes using nickel and cobalt as catalysts, whereas other groups successfully used nickel [13, 15], nickel-cobalt [14] or cobalt 11]. This may be due to several facts. First, the catalyst is usually deposited by thermal evaporation or sputtering from a pure metal source. Furthermore, the catalyst is often reduced before the growth or the growth itself is carried out in a reducing atmosphere to ensure that the catalyst remains metallic [24]. In our case however, the catalyst is dissolved in a solution. Since the printed iron catalyst consists of a gel-like material that forms a $\mathrm{Fe}_{2} \mathrm{O}_{3}$ film after annealing [12] and no step is taken to reduce the catalyst, we conclude that in our case the catalyst is not pure metal, but metal oxide. This may significantly change the behavior of the catalyst. Second, we use thermal CVD, in contrast to the Hot Filament or Plasma Enhanced CVD used in other studies. The hot filament and the plasma provides an additional possibility for the dissociation of the hydrocarbon and may decisively influence the reaction kinetics.

The electronic properties and the enormous lengthdiameter ratio of the carbon nanotubes offers the possibility to use them as field emitters [7]. The non-aligned arrangement of the carbon nanotubes is known to be even more efficient in field emission than an aligned one [25]. The emission from aligned nanotube films is lower because of screening effects between densely packed neighboring tubes and the small height of the few protruding tubes. In contrast, the non-aligned films offer well sep- arated nanotubes which do not show these effects [26]. For the sake of profitability their application in field emission displays requires glass as substrate instead of silicon, but the borosilicate glass used melts around $660^{\circ} \mathrm{C}$. Most studies carried out on catalytic nanotube growth use however temperatures above $700^{\circ} \mathrm{C}$ [11, 14], which are too high for that purpose. Choi et al. report a plasmaenhanced CVD process at a temperature of $550^{\circ} \mathrm{C}$ [15], but the diameter of these nanotubes seems quite large and lacks uniformity. We could demonstrate that the growth of thin carbon nanotubes with just a few layers of carbon starts around $620^{\circ} \mathrm{C}$, and that high quality films are obtained at $650^{\circ} \mathrm{C}$. These nanotubes have uniform diameter and well-graphitized walls which is an indicator for good field emission properties. The temperature may even be further lowered by using other gas mixtures, by using other metallic or heterogeneous catalysts [16].

\section{CONCLUSIONS}

We observed a significant influence of the temperature and the catalyst material on the quality of the carbon nanostructures. The diameter of the nanotubes and the density is adjustable by choosing the corresponding temperature and/or the concentration of the catalyst solution. Under the studied conditions iron is the best catalyst. We observed a morphology transition with temperature from multi-wall nanotubes to "carbon worms". The best nanotubes are obtained at temperatures between $650^{\circ} \mathrm{C}$ and $720^{\circ} \mathrm{C}$. Nanotubes obtained at temperatures below the melting temperature of borosilicate glass of $660^{\circ} \mathrm{C}$ are suitable as field emitters for flat panel displays.

\section{Acknowledgement}

The Swiss National Science Foundation (SNF) is acknowledged for the financial support. The electron microscopy was performed at the Centre Interdépartmental de Microscopie Electronique (CIME) of EPFL.
[1] H. W. Kroto, J. R. Heath, S. C. O'Brian, R. F. Curl and R. E. Smalley, Nature 381 (1985) 162.

[2] S. Iijima, Nature 354 (1991) 56.

[3] D. Ugarte, Nature 359 (1992) 707.

[4] S. Iijima, M. Yudasaka, R. Yamada, S. Bandow, K. Suenaga, F. Kokai and K. Takahashi, Chem. Phys. Lett. 309 (1999) 165.

[5] J. P. Salvetat, A. J. Kulik, J. M. Bonard, G. Andrew, D. Briggs, T. Stöckli, K. Méténier, S. Bonnamy, F. Béguin, N. A. Burnham and L. Forró, Adv. Mater. 11 (1999) 161.

[6] T. W. Odom, J. L. Huang, P. Kim and C. M. Lieber, Nature 391 (1998) 62.
[7] J. M. Bonard, J. P. Salvetat, T. Stöckli, L. Forró, K. Kern and A. Châtelain, Appl. Phys. A 69 (1999) 245.

[8] B. Vigolo, A. Penicaud, C. Coulon, C. Sauder, R. Pailler, C. Journet, P. Bernier and P. Poulin, Science 290 (2000) 1331.

[9] T. Guo, P. Nikolaev, A. G. Rinzler, D. Tomanek, D. T. Colbert and R. E. Smalley, J. Phys. Chem. 99 (1995) 10694.

[10] V. Ivanov, A. Fonseca, J. B. Nagy, A. Lucas, P. Lambin, D. Bernaerts and X. B. Zhang, Carbon 33 (1995) 1727.

[11] K. Hernadi, A. Fonseca, J. B. Nagy, D. Bernaerts, J.Riga and A. Lucas, Syn. Metals 77 (1996) 31. 
[12] H. Kind, J. M. Bonard, C. Emmenegger, L. O. Nilsson, K. Hernadi, E. Maillard-Schaller, L. Schlapbach, L. Forró and K. Kern, Adv. Mater. 11 (1999) 1285.

[13] Z. F. Ren, Z. P. Huang, J. W. Xu, J. H. Wang, P. Bush, M. P. Siegal and P. N. Provencio, Science 282 (1998) 1105.

[14] C. J. Lee, D. W. Kim, T. J. Lee, Y. C. Choi, Y. S. Park, Y. H. Lee, W. B. Choi, N. S. Lee, G. S. Park and J. M. Kim, Chem. Phys. Lett. 312 (1999) 461.

[15] Y. C. Choi, D. J. Bae, Y. H. Lee, B. S. Lee, I. T. Han, W. B. Choi, N. S. Lee and J. M. Kim, Syn. Metals 108 (2000) 159.

[16] A. M. Cassell, S. Verma, L. Delzeit, M. Meyyappan and J. Han, Langmuir 17 (2001) 260.

[17] A. Bernard, J. P. Renault, B. Michel, H. R. Bosshard and E. Delamarche, Adv. Mater. 12 (2000) 1067.

[18] A. Kumar and G. M. Whitesides, Appl. Phys. Lett. 63 (1993) 2002.

[19] P. C. Hidber, W. Helbig, E. Kim and G. M. Whitesides, Langmuir 12 (1996) 1375.

[20] H. Kind, J. M. Bonard, L. Forró, K. Kern, K. Hernadi, L. O. Nilson, L. Schlapbach, Langmuir 16 (2000) 6877.

[21] N.M. Rodriguez, J. Mater. Res. 8 (1993) 3233.

[22] H. Kanzow, A. Schmalz, A. Ding, Chem. Phys. Lett. 295 (1998) 525.

[23] S. J. Townsend, T. J. Lenosky, D. A. Muller, C. S. Nichols and V. Elser, Phys. Rev. Lett. 69 (1992) 921.

[24] M. Nath, B. C. Satishkumar, A. Govindaraj, C. P. Vinod and C. N. R. Rao, Chem. Phys. Lett. 322 (2000) 333.

[25] L. Nilsson, O. Groening, C. Emmenegger, O. Kuettel, E. Schaller, L. Schlapbach, H. Kind, J. M. Bonard and K. Kern, Appl. Phys. Lett. 76 (2000) 2071.

[26] J. M. Bonard, N. Weiss, H. Kind, T. Stöckli, L. Forró, K. Kern and A. Châtelain, Adv. Mater. 13 (2001) 184.

\section{Figures}



FIG. 1: SEM micrograph demonstrating the homogeneity of the patterning on a Si/SiO${ }_{2}$ sample (100 mM iron nitrate solution at $720^{\circ} \mathrm{C}$ )
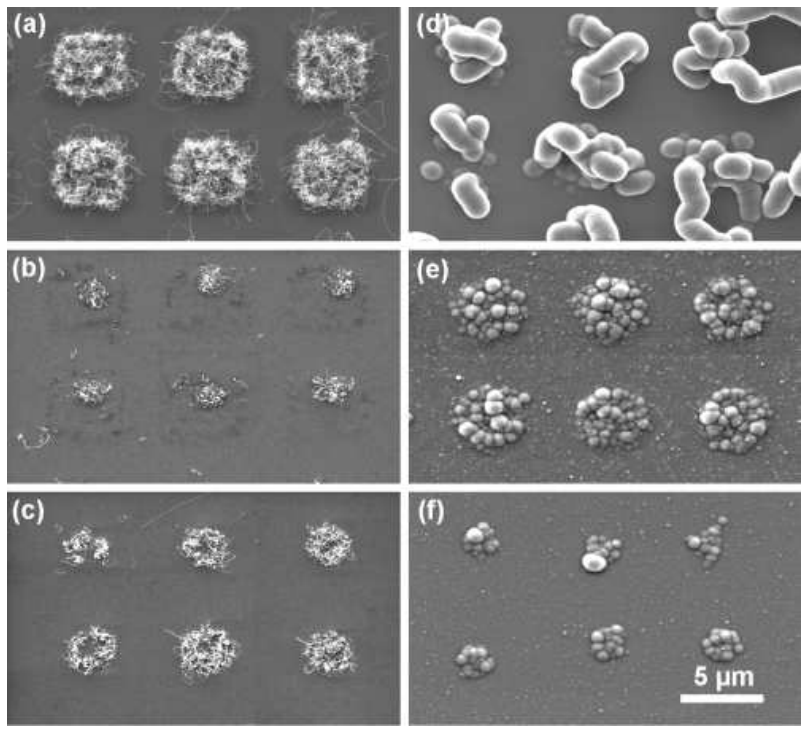

FIG. 2: SEM micrographs demonstrating the effect of the catalyst on the nanotube growth: $100 \mathrm{mM}$ solution of (a) Fe (b) $\mathrm{Ni}$ (c) Co nitrate at $720^{\circ} \mathrm{C}$ and of (d) $\mathrm{Fe}(\mathrm{e}) \mathrm{Ni}(\mathrm{f})$ Co nitrate at $1000^{\circ} \mathrm{C}$
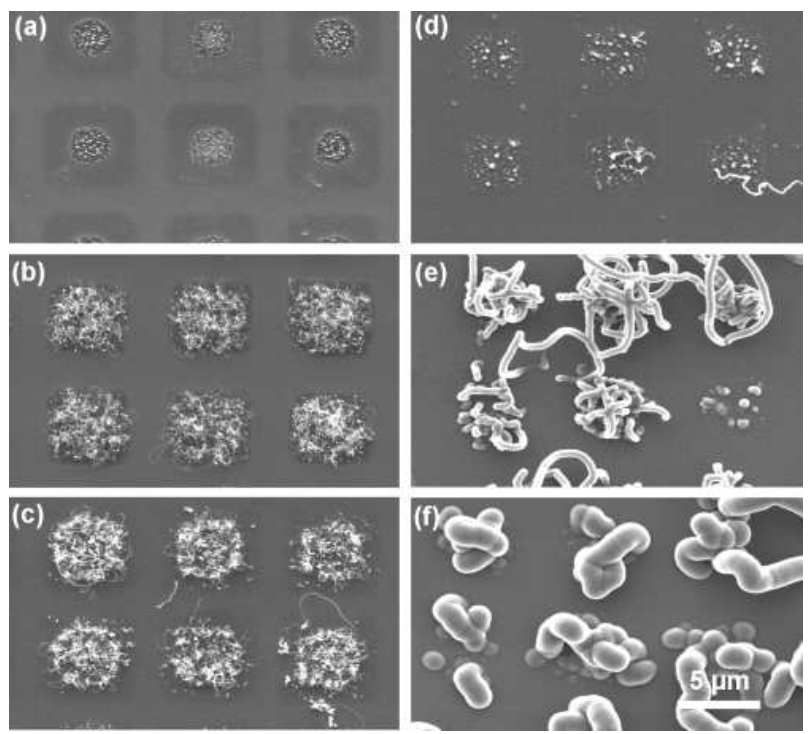

FIG. 3: SEM micrographs demonstrating the effect of the temperature on the nanotube growth: $100 \mathrm{mM}$ solution of iron $n i$ trate at (a) $580^{\circ} \mathrm{C} \mathrm{(b)} 650^{\circ} \mathrm{C} \mathrm{(c)} 720^{\circ} \mathrm{C} \mathrm{(d)} 860^{\circ} \mathrm{C}$ (e) $930^{\circ} \mathrm{C}$ (f) $1000^{\circ} \mathrm{C}$ 

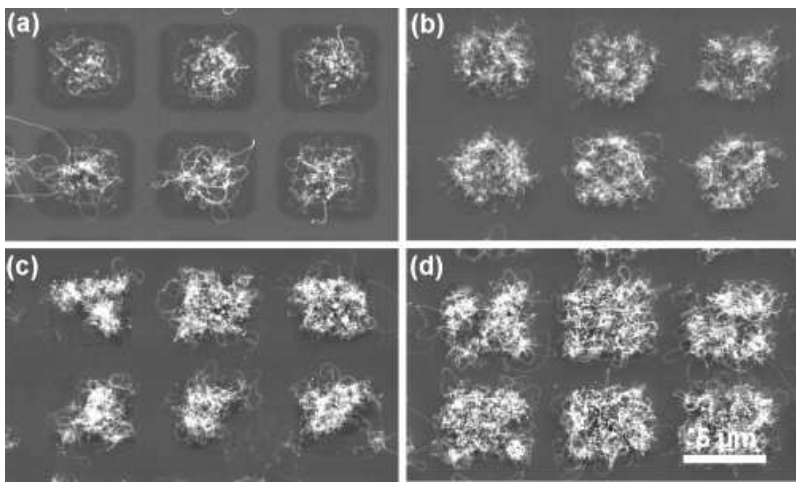

FIG. 4: SEM micrographs demonstrating the effect of the concentration on the nanotube growth: a (a) $50 \mathrm{mM}$ (b) $100 \mathrm{mM}$ (c) $150 \mathrm{mM}$ (d) $200 \mathrm{mM}$ solution of iron nitrate at $650^{\circ} \mathrm{C}$

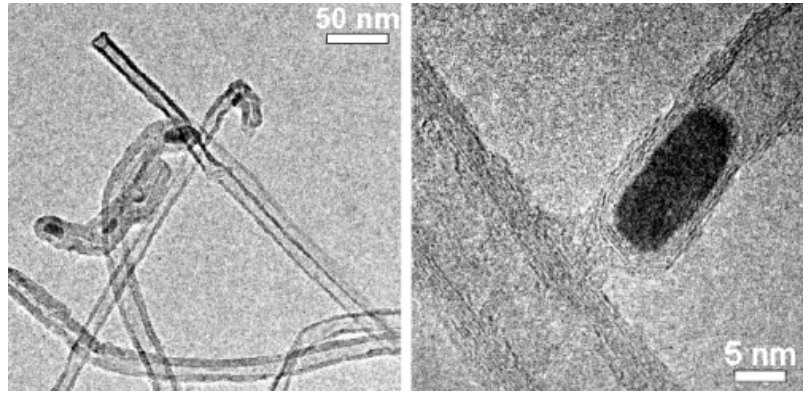

FIG. 5: TEM micrograph of individual nanotubes grown at $650^{\circ} \mathrm{C}$ with a $50 \mathrm{mM}$ iron solution. 